\title{
Subjetividade e Solidariedade: A Diversidade das Formas de Implicação dos Jovens na Economia Solidária
}

\author{
Subjectivity and Solidarity: The Diverse Ways Toung Workers Commit \\ Themselves in Social Economy Projects
}

\author{
Henrique Caetano Nardi“, Denise Balem Yates, \\ Janice Mendes Fernandes \& Manoela Carpenedo Rodrigues \\ Universidade Federal do Rio Grande do Sul, Porto Alegre, Brasil
}

\begin{abstract}
Resumo
O estudo enfoca a forma de inserção profissional e implicação no trabalho dos jovens no campo da economia solidária e do associativismo. O objetivo principal é discutir as relações entre os processos de subjetivação e a construção do ideal profissional de trabalhadores de até 30 anos. A análise das entrevistas, metodologicamente baseada na abordagem biográfica, aponta para uma diversidade das formas de compreender a relação com o trabalho e com os colegas no que se refere aos princípios da economia solidária e do associativismo. A ausência de suportes sociais (o apoio do Estado ou da sociedade civil) e a sustentabilidade financeira dos projetos influenciam nas formas dos trabalhadores aderirem (ou não) ao modelo de gestão solidário. A análise das entrevistas e o acompanhamento dos projetos indicam que os princípios da autogestão são parcialmente efetivados, existindo uma tendência a reproduzir relações hierárquicas e paternalistas.

Palavras-chave. Economia solidária; jovens; trabalho; subjetividade; autogestão.
\end{abstract}

\begin{abstract}
This article discusses the way young professionals enter and commit themselves in the social economy and associative work field. The main objective is to understand the relationships between the process of subjectification and the construction of the professional ideal among workers up to 30 years old. The analysis of the interviews, methodologically based on the biographical approach, indicates a great diversity of ways of comprehending work relationships, concerning the principles of social economy and associativism. Lack of social support (from government or civil society) and financial sustainability of projects influence in the way young workers cohere to the model of social economy management. The analysis of the interviews and the long-term observation of the projects indicate that self-management principles are only partially accomplished, existing a tendency to reproduce paternalist and hierarchical relationships.

Keywords: Social economy; young workers; work; subjectivity; self-management.
\end{abstract}

A relação entre subjetividade e trabalho remete à análise da maneira como os sujeitos vivenciam e dão sentido às suas experiências de trabalho (Nardi, Tittoni \& Bernardes, 2002). A interpretação dessa relação nos coloca frente à especificidade histórica assumida pela relação dos sujeitos com seu trabalho em cada contexto socioeconômico e cultural. Cada tempo e cada contexto social definem diferentes modos de subjetivação. Este conceito se refere à maneira predominante pela qual os sujeitos relacionam-se com as regras e as verdades que dão sentido à existência a partir da construção de uma determinada experiência de si (Foucault, 1994). Assim, os sentidos atribuídos ao trabalho mudam se analisarmos a relação do cidadão e do escravo com o trabalho na Grécia, do senhor de engenho com o escravo no Brasil Colonial, do operário e do patrão no modelo industrial fordista, do jovem trabalhador autô-

"Endereço para correspondência: Instituto de Psicologia, Rua Ramiro Barcelos, 2600, Porto Alegre, RS, 90035-003, Brasil. Fone/Fax: (51)3330 8628. E-mail: hcnardi@terra.com.br Apoio Institucional: $\mathrm{CNPq}$ (apoio à pesquisa e PIBIC), FAPERGS, Auxílio Recém Doutor (ARD) e bolsas de IC (BIC e PROBIC) nomo da nova economia no século XXI e daqueles que inserem nos projetos de economia solidária (ES), nosso caso de análise.

A ES pode ser definida como uma forma de geração de renda, trabalho e inserção social baseada na solidariedade e na cooperação que ressurge na virada do milênio devido à nova configuração do mercado de trabalho contemporâneo (pode-se falar em ressurgimento, pois experiências semelhantes surgiram no século XIX na Europa). A ES pode também ser compreendida como um movimento social que luta contra as conseqüências da desregulamentação econômica e do movimento global de reestruturação produtiva (Albuquerque, 2003). Assim, a ES tenta oferecer uma solução ao desemprego, à desfiliação da rede de proteção do Estado ligada à legislação trabalhista (Castel, 1998) e ao incremento da parcela dos "nunca filiados". Termo utilizado por Nardi (2003) para definir a condição dos trabalhadores que nunca foram integrados a qualquer forma de suporte social para a existência, situação comum no Brasil e que distingue nosso mercado de trabalho daquele próprio à sociedade salarial, componente fundamental do modelo de Estado Social europeu. 
Este movimento solidário propõe uma forma de inserção social e organização do trabalho alternativa ao atual modelo econômico. A solidariedade, seu princípio fundamental, se constrói, de acordo com Singer (2003), nas relações estabelecidas entre os membros das organizações através da prática da autogestão e do companheirismo.

A autogestão, para o autor, consiste na igualdade de direitos entre os membros dos empreendimentos e na repartição do capital entre todos de forma igualitária. A construção da solidariedade se materializa pela priorização da organização de cooperativas formadas por desempregados e trabalhadores em vias de perder o emprego nas camadas mais pobres da população. Em uma perspectiva para além dos projetos, a solidariedade se efetiva pelo auxílio a pessoas em situação de vulnerabilidade. Para Icaza e Tiriba (2003) a ES nasce da economia popular, pois estabelece relações sociais:

calcadas nos valores de comensalidade, reciprocidade e cooperação, os atores da economia popular criam estratégias de trabalho e sobrevivência que visam não apenas a obtenção de ganhos monetários e excedentes que possam ser trocados no mercado, mas também a criação de condições que lhes favoreçam alguns elementos que são fundamentais no processo de formação humana, como a socialização do saber e da cultura, saúde, moradia, etc. (p. 101).

A retomada da autogestão é concebida de duas maneiras: por um lado, esta assume uma conotação fortemente econômica, como forma de salvar empresas da falência e evitar o desemprego em massa (Pires, 1999), sendo as iniciativas da ES consideradas apenas uma forma alternativa de geração de renda no capitalismo (Lima, 2001 citado em Ferraz, 2004), nas quais o sentido de solidariedade se faria presente devido a um interesse comum de reinserção social. Por outro lado, ela também é compreendida como uma retomada de lutas políticas e ideológicas por um ideal de mudança social (Singer, 2000), visto que essa nova atividade econômica teria como finalidade a realização de objetivos sociais em detrimento do acúmulo de capital e que, aos poucos, esta estratégia de sobrevivência poderia se transformar numa alternativa social, econômica e política (Icaza \& Tiriba, 2003). De forma sintética podemos afirmar, de acordo com Gaiger (2004a), que o movimento da ES propõe oito princípios: autogestão, democracia, par ticipação, igualitarismo, cooperação, auto-sustentação, desenvolvimento humano e responsabilidade social.

Por essa razão, Laville (1999) afirma que a dimensão social deve estar permanentemente articulada com a dimensão econômica e com a dimensão política na caracterização do fenômeno da ES, pois nessas iniciativas os indivíduos não se comportam unicamente como atores econômicos; trata-se de membros de famílias ou de comunidades que são igualmente cidadãos na esfera política.

Entretanto, as condições de implantação dos projetos esbarram em condições de vulnerabilidade social que dificultam a participação política dos participantes dos empreendimentos. Segundo Cruz (2002), na maioria dos casos no Brasil:
O público alvo dos programas é composto pelo extrato populacional mais frágil sob todos os pontos de vista: são os deserdados do capital, do conhecimento e do poder. São pessoas que precisam resolver o problema de sua alimentação no dia seguinte, sempre. Mas ainda não é só: sua cultura é a cultura da subordinação, do clientelismo, do assalariamento, da desproteção, do individualismo. Não é a cultura da coletividade, da solidariedade (Cruz, 2002, p. 11).

O autor afirma que as condições de alienação em que se produz e reproduz o cotidiano dos programas estão longe de permitir a compreensão dos adversários externos, ou seja, a concorrência selvagem do mercado, a perseguição das instituições controladas e/ou condicionadas pelo grande capital e a ausência de apoios institucionais eficazes.

Para Icaza e Tiriba (2003), o termo ES aparece inicialmente como expressão de um projeto e não necessariamente de uma realidade efetivamente existente. Imersa na lógica capitalista, mesmo a proposta da ES acaba sendo retomada com o objetivo de dar conta da falência da oferta de pleno emprego, não se constituindo como uma alternativa, mas como "a última saída", especialmente no Brasil. Isto provoca uma série de contradições que ficam explícitas na significação que os trabalhadores da ES dão para sua atividade profissional, muitas vezes marcada por uma relação instrumental com os projetos/empreendimentos, como veremos na discussão dos relatos.

Existem também outros paradoxos na ES contemporânea, no que se refere à autogestão. Embora a origem do termo remeta à gestão coletiva e democrática do empreendimento, as cooperativas necessitam de um suporte externo, geralmente concedido através de verbas governamentais. Não se está questionando o apoio ou o financiamento do Estado aos empreendimentos solidários, mas sim o risco da ingerência ou de interferência na democracia interna dos projetos e na autogestão. Outro dilema se situa na necessidade de garantir um determinado nível de produtividade que possibilite a sobrevivência do empreendimento. Isto pode criar uma contradição entre a forma de organização do projeto e a necessidade de uma postura competitiva no mercado, confrontando racionalidades nem sempre facilmente assimiláveis. Ou seja, uma tensão entre a condição ideal de cooperação e uma lógica de mercado que prioriza o individualismo e altos índices de produtividade e lucratividade.

Os vários tensionamentos que atravessam o caráter de movimento social e de "solução imediata de um constrangimento econômico" (Costa, 2003, citado em Ferraz, 2004) da ES denotam que esse novo conceito engloba um fenômeno complexo marcado por diversas lógicas de organização e atuação.

O quadro contemporâneo de implantação dos projetos de ES se situa, portanto, na contradição entre os princípios da ES apregoados pelos líderes do movimento e a heteronomia imposta pela economia de mercado. A efetivação destes princípios dependeria, no nosso entendimento, de um processo de redefinição das formas de atribuição de sentido ao trabalho para que os valores da autogestão e da solidariedade possam reconfigurar os modos de 
subjetivação associados à competitividade, ao modelo de gestão e ao individualismo no capitalismo contemporâneo (Bauman, 2000; Boltanski \& Chiapello, 1999; Castel, 1998; Durand, 2003; Erhemberg, 2000; Petras, 1999; Sennett 1998).

É buscando compreender as tensões presentes entre os princípios propostos pela ES e os modos de subjetivação associados ao capitalismo globalizado que este artigo tem por objetivo analisar vinte trajetórias de vida de trabalhadores de projetos de ES e do associativismo em Porto Alegre e cidades vizinhas. Procuramos investigar como a proposta da ES se manifesta nestes empreendimentos e quais as formas de implicação destes jovens no trabalho. Nesta direção, identificaremos a regularidade e a diversidade presentes nos relatos e sua relação com a construção do ideal profissional e com o contexto socioeconômico no qual se inserem os projetos analisados.

\section{Método}

A abordagem biográfica (Cabanes, 2002) foi utilizada neste estudo com o objetivo de compreender os diversos fatores que configuram a inserção profissional e o significado do trabalho. Essa abordagem possibilitou esclarecer como os indivíduos construíram suas vidas a partir da inserção (ou da tentativa de) no mercado de trabalho. Além disso, com o auto-relato, nos aproximamos da visão de mundo do(a) entrevistado(a), ou seja, como ele(a) dá sentido à sua participação na história social e cultural de seu tempo. De acordo com Carvalho (2003), a abordagem biográfica opera no interjogo entre a privacidade de um sujeito e o espaço sócio-histórico de sua existência. Dessa forma, podemos compreender o trabalho como um dispositivo que atravessa os modos de subjetivação dos trabalhadores, bem como os julgamentos morais que conduzem ao engajamento no laço social, elemento fundamental para a efetivação dos princípios da ES

A análise da construção das "individualidades em interação" estuda o espaço ocupado pelo sujeito no contexto social, uma posição que se constrói não como um dado definitivo, não como uma posição fixa na estrutura social, mas como um processo. Cabanes afirma: "o relato biográfico - récit biographique - permite efetuar a primeira parte do projeto que é a condição para a análise da construção social da relação consigo mesmo" (2002, p. 417). A utilização da noção de ideal de nós (idéal de nous), proposta pelo autor, e derivada do conceito de "ideal de eu” (Laplanche \& Pontalis, 1998), é bastante frutífera na análise das trajetórias de vida, uma vez que remete a um ideal de construção societária/comunitária ou de grupo de pertencimento. Assim, para além dos fatores que induzem a um determinado destino social comum, o estudo se atém à compreensão das singularidades de cada história. No caso analisado é um determinado ideal coletivo de trabalho que está em questão e que marca cada trajetória de forma distinta.

Ao se buscar uma abordagem interdisciplinar, a análise das entrevistas foi guiada metodologicamente pela leitura compreensiva tal como descrita por Bourdieu (1993). Nessa abordagem a análise se centra basicamente na confrontação contínua das experiências e das reflexões dos participantes envolvidos no estudo. Ao propor a reflexividade reflexa como procedimento para a compreensão, o processo implica na tensão permanente entre o ponto de vista do entrevistador e o ponto de vista do entrevistado, ou seja, como a visão de mundo do pesquisador apreende a visão de mundo presente no relato da trajetória de vida. Para o autor, o processo de pesquisa é incontestavelmente uma relação social. Portanto, a interação (condições institucionais da pesquisa, origem do pesquisador, locus social do pesquisado) possui, inevitavelmente, efeitos sobre todos os participantes; fatores esses que devem ser percebidos, compreendidos e analisados, sem a pretensão de eliminá-los.

Neste sentido, nossa abordagem incorporou uma escuta ativa e metódica, intermediária entre a pura não-intervenção e o intenso dirigismo de um questionário fechado. Ao longo da análise, buscamos identificar as relações entre os sujeitos entrevistados e seu trabalho; demarcando os dispositivos que atuam nos processos de subjetivação e balizam os parâmetros éticos. Ainda, e como forma de dar maior consistência para análise e ampliar a compreensão do contexto no qual estão inseridos os jovens entrevistados, nosso trabalho de campo incluiu a observação do cotidiano de trabalho, além da análise dos documentos (estatutos) dos projetos.

Analisaremos, em seguida, as trajetórias de vida de 20 trabalhadores participantes da ES e de associações, divididos em três grupos: galpão de triagem, cooperativa industrial e telecentro/rádio comunitária. Estabelecemos um ponto de corte na idade dos entrevistados em 30 anos que, apesar de não configurar a definição de jovem para o Instituto Brasileiro de Geografia e Estatística (IBGE), reflete de certa forma a ampliação da idade de ingresso no mercado de trabalho (Petras, 1999) e permite que nos restrinjamos a um determinado recorte geracional. Não apresentaremos os relatos integrais das entrevistas, pois não haveria espaço no artigo. Como alternativa à forma clássica de apresentação das trajetórias de vida, buscaremos identificar as características centrais de cada grupo, assim como suas peculiaridades e diferenças internas. Discutiremos de forma conjunta a história, o contexto dos projetos e os relatos dos trabalhadores.

\section{Resultados: Contexto dos Projetos e Trajetórias de Vida}

\section{Galpão de Triagem}

O grupo de entrevistados é composto por cinco trabalhadores (três mulheres e dois homens) de um Galpão de Triagem localizado na periferia de Porto Alegre. O projeto começou em um "lixão", no qual não havia as mínimas condições de trabalho. Segundo relatos dos entrevistados, após 4 anos de luta, a comunidade conquistou o galpão através do Orçamento Participativo. A partir daí os trabalhadores formaram uma associação que passou a fazer parte 
Nardi, H.C., Yates, D.B., Fernandes, J.M., \& Carpenedo, M. (2006). Subjetividade e Solidariedade: A Diversidade das Formas de Implicação dos Jovens na Economia Solidária.

do Programa de Economia Popular Solidária da Prefeitura de Porto Alegre - Programa Reciclar - no qual o Departamento Municipal de Limpeza Urbana (DMLU) se encarrega de encaminhar o lixo recolhido para as unidades de triagem. Essa associação faz parte do Movimento Nacional dos Catadores de Material Reciclável (MNCR) que reúne vários empreendimentos. Um dos frutos da luta do movimento foi um financiamento do Estado chamado "Frentes de Trabalho" que corresponde a seis parcelas de R\$280,00 para cada trabalhador. A luta do MNCR é pelo reconhecimento dos catadores como trabalhadores, valorizando o trabalho ecológico que fazem. Entretanto, a relação com a prefeitura não é tranqüila, pois existe uma disputa entre o MNCR e o DMLU envolvendo a definição das formas de organização do trabalho nos galpões.

No Galpão de Triagem trabalham 50 pessoas, distribuídas em dois turnos de 6 horas cada. As principais atividades dos associados são trabalhar nas mesas de triagem, nas prensas e na direção. A direção da associação é composta pelos próprios catadores, nos cargos de presidente, vice-presidente, secretária, vice-secretária, tesoureiro, vicetesoureiro e dois fiscais. Geralmente, seus integrantes é que participam das reuniões de caráter político com outras organizações. Os trabalhadores reúnem-se em assembléia uma vez por mês para decidir os rumos do projeto.

A renda é proporcional à produção da quinzena, mas o preço do material é baixo, aliado à má qualidade do mesmo, o que proporciona um pequeno retorno financeiro (a média quinzenal é de $\mathrm{R} \$ 65$, 00 por trabalhador). Isso ocasiona uma alta rotatividade e baixa adesão ao projeto, contribuindo para problemas de relacionamento, auto-estima depreciada e falta de motivação para o trabalho. Além disso, os catadores convivem com vários riscos para sua saúde e não possuem equipamentos de proteção individual ou coletiva. Percebemos também que a pressão para o incremento da produtividade está presente com bastante força dentro do galpão. Há cobrança, pois a renda depende disso.

A democracia interna e a autogestão, princípios apregoados pelos líderes da ES, têm dificuldade de implantação neste empreendimento. Na primeira assembléia que acompanhamos percebemos uma grande dificuldade de comunicação entre os trabalhadores e a direção. A presidente mantinha relações autoritárias com os associados, o que não favorecia a participação, levando ao desinteresse e o descontentamento do grupo. Os trabalhadores se queixavam de que a pauta da assembléia já vinha pronta e que, dessa maneira, não era possível que as pessoas se expressassem. Notamos que a direção falava muito no regimento da associação e cobrava o seu cumprimento, entretanto, os trabalhadores não tinham claro seu conteúdo e, portanto, não tinham liberdade para discuti-lo e modificá-lo.

Segundo os relatos, há uma obrigação de comparecer às reuniões com a prefeitura, sendo que a ausência implica na perda dos rendimentos equivalentes a dois dias de trabalho. Uma das trabalhadoras afirmou que não adiantava ir e "não abrir a boca", já que o ideal seria participar efe- tivamente. Outros disseram que não se procura conscientizar os trabalhadores da necessidade de participação e que "os tratam como bichos". Quando eles votaram essa pauta, decidiram que quem não fosse perderia apenas um dia de trabalho. A presidente não ficou muito satisfeita, pois disse que com uma menor punição as pessoas não iriam querer participar. Percebe-se que a direção não estabelecia um diálogo efetivo com os trabalhadores e, assim, emperrava a construção da autogestão. Assim, se de acordo com os líderes do movimento, um dos princípios da ES é a autogestão, a análise da assembléia nos leva a pensar que este processo ainda não foi construído por esse coletivo, imperando a verticalização das relações de poder. Singer (2000) afirma que para a efetivação da autogestão em um empreendimento solidário, os conflitos devem ser tratados abertamente e resolvidos em negociações coletivas, das quais todos os trabalhadores fazem parte; as ferramentas da gestão deveriam ser apropriadas por todos e só desta forma, permitiriam aos coletivos decidir sobre os rumos de seu trabalho e de sua produção.

No caso analisado, havia um descontentamento por parte dos associados, pois a direção não costumava prestar contas. De imediato, percebe-se que não é simples potencializar a invenção de outros modos de trabalhar em um contexto econômico, onde a necessidade de sobrevivência coloca-se como imperativo. As relações no galpão de triagem reproduzem as relações de dominação presentes no mercado de trabalho tradicional.

O acompanhamento do trabalho cotidiano do galpão de triagem e das assembléias no período de novembro de 2003 a novembro de 2004 permitiu que tivéssemos uma visão mais aprofundada dos problemas e necessidades desses trabalhadores. Neste tempo, percebemos uma transformação na maneira como os trabalhadores se posicionavam em relação à direção e uma maior proximidade que construíram em relação ao MNCR. Este fato levou à exigência de algumas assembléias para prestação de contas, coordenadas pela equipe do MNCR. Nestas, foi constatada a existência de roubo e a presidente e a tesoureira foram afastadas da associação, sendo eleita uma nova direção. A nossa avaliação em relação a esse processo é que foi de fundamental importância o apoio dado pelo MNCR, pois os trabalhadores se encontravam fragilizados e imersos em uma lógica autoritária. Atualmente, os trabalhadores se encontram num processo de reorganização e parece haver uma maior horizontalidade nas relações de trabalho.

As trajetórias dos entrevistados são caracterizadas por escolaridade média de sete anos de estudo formal, repetindo o grau de escolaridade atingido por seus pais. Os trabalhadores já exerceram uma série de atividades sem vínculo empregatício. A dificuldade de inserção no mercado formal é fruto da baixa escolaridade associada a condições socioeconômicas precárias, reproduzindo a história familiar. $\mathrm{O}$ valor do trabalho transmitido pelos pais prioriza a sobrevivência em detrimento do trabalho como valor em si.

Em relação ao trabalho na época de seus pais e hoje, relatam que "o mercado de trabalho antigamente tinha 
muitas oportunidades e dava experiência pro pessoal mais jovem. Agora não tem nenhuma oportunidade e não se dá experiência pros jovens". Segundo uma das entrevistadas "os pais trabalhavam menos e ganhavam aquilo que eles precisavam trabalhando. Agora as pessoas trabalham bastante e ganham pouco e as coisas estão muito caras hoje em dia”. Acreditam que as oportunidades de trabalho mudaram para pior, pois está cada vez mais difícil conseguir um "serviço". Exige-se qualificação e só tem chance "aqueles que têm estudo". O ingresso no mercado de trabalho foi marcado pela desilusão e insatisfação, uma vez que a definição do trabalho ideal remete para a desvalorização do trabalho físico nas condições em que ele é opor tunizado para estes trabalhadores. Enquanto para uns o trabalho ideal é aquele no qual se tem prazer em trabalhar, para outros é aquele no qual se recebe um salário fixo, se têm os direitos trabalhistas assegurados e a valorização da chefia. Em nenhum dos casos foi relatada experiência que preenchesse estes critérios.

A maior parte dos trabalhadores deseja permanecer num mesmo local de trabalho por muito tempo e fazer carreira, com exceção dos que preferem ter um negócio próprio. Questionados se sentem orgulho do trabalho que fazem, a maioria afirma que se orgulha em estar contribuindo para deixar o mundo mais limpo e cuidar do meio ambiente. Entretanto, é o trabalho como forma de sobrevivência que surge como principal razão de permanência na atividade. Para estes jovens, a dificuldade de incorporação da autogestão como um princípio, se associa a uma multiplicidade de fatores, entre eles, a instabilidade na geração de renda. A instabilidade faz com que os trabalhadores não considerem o galpão como uma alternativa viável em longo prazo, este fato, reforça, ao mesmo tempo, a tensão entre o desejo de estabilidade idealizado na imagem do emprego tradicional e as condições duras e precárias do trabalho cotidiano no galpão. Assim, os valores tradicionais presentes no imaginário social prevalecem sobre aqueles apregoados pelo movimento da ES.

\section{Cooperativa Industrial}

O grupo de entrevistados é composto por dez trabalhadores (nove homens e uma mulher) de uma cooperativa industrial de uma cidade próxima a Porto Alegre. Os trabalhadores desta cooperativa foram escolhidos para fazer parte da pesquisa devido à trajetória do empreendimento, bastante conhecida na área da ES. Um dos motivos que nos levou a investigar uma indústria se devia à necessidade de diversificar as formas de ES estudadas, tendo em vista que o galpão de triagem de lixo evidenciava uma forma de inserção precária.

Uma das características que distinguem estes dois locais diz respeito aos estatutos que regulam as associações e as cooperativas. Além disso, esta cooperativa é um empreendimento mais estruturado, pois os trabalhadores haviam assumido a massa falida da empresa. A cooperativa tem uma trajetória semelhante a outras indústrias que se transformaram em projetos de ES (Holzmann, 2001). De acordo com as informações colhidas nas entrevistas com seus atuais dirigentes, após um longo período de sucesso, a empresa da qual se origina a atual cooperativa começou a ter os primeiros problemas financeiros na década de 80 . Nesta época os funcionários passaram a receber salários atrasados e não terem garantidos seus direitos trabalhistas.

A falência da empresa ocorreu em 2001, entretanto, durante toda a década de 90 , o sindicato discutiu a proposta de transformação da empresa em cooperativa sem a aceitação dos trabalhadores, o que pode ser entendido como o receio de se lançar em projeto distinto daquele da lógica do vínculo empregatício.

Em novembro de 2001 a cooperativa foi formada como única solução para garantir uma parcela dos postos de trabalho, começando a funcionar em março de 2002. O grupo alugou os prédios, as máquinas e a marca da indústria por um período de cinco anos. Os recursos para recolocar a indústria em funcionamento foram obtidos através de um empréstimo junto ao governo do estado. $\mathrm{O}$ valor disponibilizado pelo banco foi bastante aquém do que seria necessário. Este fator, no momento das entrevistas, se relacionava à impossibilidade de investimento em tecnologia, acarretando em uma produção quase artesanal que reduzia a margem de lucro e as possibilidades de geração de renda de forma estável e suficiente para os trabalhadores.

Muitos dos funcionários da antiga empresa foram buscar alternativas de trabalho assalariado, enquanto cerca de 300 trabalhadores da época se associaram à cooperativa. A estrutura hierárquica permanece bastante marcada nas relações entre os trabalhadores, como fica claro em diversos aspectos observados. Começando pela arquitetura do local, no qual a disposição das salas e dos móveis remonta à década de 70: a gerência e o setor administrativo ficam no andar superior à produção, com grandes janelas que permitem supervisionar o trabalho na fábrica. Nos relatos dos trabalhadores da produção que faziam parte da empresa antes da falência, percebe-se um profundo respeito pela trajetória de luta e resistência da direção da cooperativa, já que se mantiveram no local mesmo com a escassez de recursos financeiros, dando a oportunidade de que muitos trabalhadores permanecessem trabalhando. Entretanto, com o passar do tempo mistura-se ao respeito certo grau de desconfiança com relação ao grupo da administração, como se, de companheiros de trabalho, os membros da direção tivessem se tornado patrões. A direção percebe que apesar de terem sido eleitos pelos trabalhadores da produção, existe um distanciamento produzido pelo afastamento do chão de fábrica destes e de um receio dos trabalhadores da produção de que tenha ocorrido a reprodução das posições de poder patrão/empregado.

O relato de alguns diretores sugere que este distanciamento seja também provocado pela concepção acerca do que significa dirigir o empreendimento. Muitas vezes afirma esta posição de liderança, cuja responsabilidade é guiar o grupo da produção para o caminho de desenvolvimento da cooperativa, utilizando termos como "empre- 
Nardi, H.C., Yates, D.B., Fernandes, J.M., \& Carpenedo, M. (2006). Subjetividade e Solidariedade: A Diversidade das Formas de Implicação dos Jovens na Economia Solidária.

endedorismo" e "defesa dos excluídos". A contradição que emerge deste contexto se evidencia pela defesa do cooperativismo e pelo apelo a um maior engajamento do grupo da produção associados à posição assimétrica da direção em relação aos demais associados, como se estes pudessem sozinhos decidir sobre a melhor forma de realizar este processo.

A diferença entre estes grupos também se evidencia no fato de existirem cinco níveis salariais na divisão dos rendimentos entre os associados, o que faz com que o diretor da cooperativa receba entre quatro e cinco vezes mais do que o trabalhador de chão de fábrica. Aqui se mantém uma lógica de remuneração que reproduz a organização hierárquica (diferentemente do galpão de triagem, no qual a renda é distribuída de forma igualitária).

Além da divisão salarial, o grupo da administração geralmente recebe apoio familiar e financeiro para seu sustento, ou tem outra fonte de renda que lhe garanta maior estabilidade. Por sua vez, a maior parte dos trabalhadores da produção entrevistados estava desempregada antes de entrar na cooperativa e estes jovens são, geralmente, os responsáveis pelo provento da família. Esta diferença também teve impacto no nível de escolaridade dos trabalhadores, pois os trabalhadores da administração que tinham maior suporte familiar conseguiram concluir o ensino médio. Entre os trabalhadores da produção, a média de escolaridade não ultrapassa o ensino fundamental.

Muitos dos associados são ex-funcionários da empresa, tendo idade média acima dos 40 anos. Como nossa pesquisa definiu um ponto de corte de 30 anos, vários dos jovens entrevistados haviam entrado na cooperativa há pouco tempo. Este é um fator que parece influenciar na implicação destes em seu trabalho, uma vez que os associados que já trabalhavam na empresa antes da falência ou entraram na fundação da cooperativa, em 2002, demonstram maior apreço pelo empreendimento do que aqueles que ingressaram no mesmo há poucos meses. Estes geralmente têm pouco conhecimento a respeito da história ou da organização da cooperativa. Alguns sequer percebem que os procedimentos adotados na empresa fogem aos princípios da autogestão, como a entrada de trabalhadores por indicação de conhecidos na cooperativa ou o desligamento de associados feito por uma comissão interna, sem votação na assembléia geral. Contudo, esse desconhecimento não é exclusividade dos trabalhadores mais novos. Alguns entrevistados com mais tempo de trabalho não diferenciam as características do empreendimento que fazem parte dos princípios da ES de formas de gestão comuns a outras empresas do setor metalúrgico.

Quanto à implicação com o trabalho, a maioria dos entrevistados ressalta sua função como meio de garantir a sobrevivência e como valor moral. Muitos consideram que o trabalho transforma "o homem", tornando-o mais experiente e responsável, permitindo que se integre à sociedade. Citando um dos jovens: "a vida se constrói em cima do trabalho. Tu tem que trabalhar pra construir teu próprio caminho. Tu tem que trabalhar para te conscientizar do que é certo e do que é errado". Nessa concepção, a experiência de trabalho se associa à ética do trabalho vinculada à ética do provedor e à cidadania tal como descrita por Colbari (1995), ou seja, a forma como o trabalho foi valorizado na cultura brasileira. Os entrevistados relatam que este modelo lhes foi transmitido pelos pais, que os ensinaram a serem justos e disciplinados, sabendo obedecer aos superiores. Assim, a lógica da subordinação também se impõe pela via familiar como intrínseca ao dever do trabalhador, tornando-se um obstáculo para o estabelecimento de relações de poder menos hierárquicas.

Contrastando com esta associação entre trabalho e disciplina, os entrevistados ligados à direção da cooperativa afirmam que existe maior liberdade para realizar funções e desenvolver idéias em uma cooperativa do que em uma empresa tradicional. Para o conjunto dos entrevistados, entretanto, as vantagens da autogestão são: (a) menor competitividade entre os colegas do que no mercado formal, (b) menor pressão hierárquica para o cumprimento de metas, (c) e o fato do lucro ser partilhado pelo conjunto dos trabalhadores.

Apesar destas vantagens, a maioria daqueles responsáveis pelo sustento da família optaria por um emprego formal em detrimento da participação na cooperativa, devido à possibilidade de ter um sustento regular aliado à garantia de direitos trabalhistas. Estes permanecem na cooperativa considerando-a como uma oportunidade momentânea de trabalho e não por ser um empreendimento solidário. Este fator pode explicar que a implicação no trabalho se dê de uma forma diferente daquela idealizada pelo movimento da ES. Esta forma mais instrumental de implicação pode nos ajudar a compreender a alta rotatividade observada nos projetos que investigamos.

Quanto às chances de entrada no mercado, a maioria afirma que a oferta de trabalho atualmente é bastante restrita, uma vez que muitos dos entrevistados passaram meses sem emprego, experiência que definem como "enlouquecedora”. Segundo os jovens, as qualidades necessárias para conseguir trabalhar em empresas tradicionais são: formação, experiência anterior e idade inferior a 35 anos. Alguns destacam o contraste entre este perfil e sua própria trajetória, e consideram a ES como saída econômica para pessoas "excluídas do modelo tradicional de sociedade".

$\mathrm{Na}$ fala daqueles que tiveram dificuldade de inserção no mercado de trabalho, a vulnerabilidade decorrente da situação de desemprego parece funcionar como condição para ingressar nos projetos de ES; sendo assim, a participação não se configura como uma escolha de vida motivada pelos princípios que regem a $\mathrm{ES}$, mas sim como um dos caminhos possíveis para estes sujeitos, mesmo que a opção pelo mercado formal seja preferencial. Poucos consideravam os princípios da ES como o principal motivo para a permanência na cooperativa com exceção dos que trabalhavam na direção. Esse grupo se divide entre trabalhadores que valorizam os princípios de distribuição de renda e gestão democrática e os que consideram a ES um meio de aumentar as vagas de trabalho. Entre os últimos, 
há os que empregam o discurso em defesa da ES pela necessidade de se manter trabalhando. Nestes entrevistados, fica aparente a crença na meritocracia, na qual a pessoa considera seu potencial individual o único responsável por sua trajetória dentro do empreendimento. Assim, constrói-se um entendimento que repete e reforça a divisão hierárquica.

$\mathrm{Na}$ expectativa com relação ao futuro dos jovens, todos desejam poder adquirir uma maior estabilidade e melhores condições de vida, através da aquisição de bens como casa, carro e outros itens de consumo. Os jovens mais vinculados à cooperativa esperam no futuro, além de satisfazer suas necessidades de conforto, poder ampliar esta experiência através da criação de novos empreendimentos que possam acolher trabalhadores que estejam fora do mercado formal.

\section{Associativismo Comunitário}

Distinguindo-se das iniciativas solidárias anteriormente abordadas, o telecentro e a rádio comunitária ilustram novas maneiras de inserção profissional para jovens desprovidos de formação ou oportunidade no mercado formal. Assim, a partir de iniciativas da própria comunidade ou do Estado, são geradas novas formas de ingressar no mundo do trabalho, porém estas não necessariamente garantem renda aos seus participantes. O grupo analisado é composto por 5 jovens ( 4 homens e 1 mulher): quatro participantes do projeto telecentro e um participante da rádio comunitária. Os projetos em questão surgem de mobilizações sociais e a proposta de inclusão digital (telecentro) que recebe apoio do município.

A implantação do telecentro, segundo um dos entrevistados, partiu de uma iniciativa da prefeitura - via orçamento participativo - juntamente com algumas entidades assistenciais. Com o incentivo dessas foi possível comprar o equipamento necessário. O respaldo municipal ainda está presente na manutenção e no suporte aos monitores, além da oferta de bolsas para dois menores aprendizes e um monitor adulto; a comunidade ficou encarregada de arcar com o espaço, bem como as contas de luz, água, limpeza e segurança do local. A proposta, de acordo com o relato, está ligada a um projeto social que foi criado com o objetivo de "socializar e qualificar as comunidades mais carentes”, já que o analfabetismo digital é um marco divisório em nossos tempos. A possibilidade de acesso à internet seria um fator facilitador, a fim de se estimular a população da região a buscar conhecimento. Outra motivação para a criação do espaço estaria ligada à ampliação de possibilidades de lazer para os jovens da comunidade visando a diminuir o consumo de drogas, bem como a criminalidade.

O projeto iniciou recebendo somente voluntários para o trabalho de monitoria; no entanto, em outubro de 2003 - época das entrevistas com os participantes - três dos voluntários passaram a receber bolsas do município; os demais voluntários atuam na espera de novas bolsas.

A rádio comunitária teve origem em 97. Segundo o relato, sua viabilização foi possível graças à doação de cachês de um evento promovido na região. Sendo assim, com o dinheiro arrecadado, foi comprado o transmissor da rádio; essa, logo, se instalou em uma igreja da região mudando-se posteriormente para o centro comunitário. Os trabalhadores da rádio não recebem qualquer tipo de remuneração.

Devido à diferença de vínculos (bolsas e voluntariado) percebe-se uma diversidade de implicação profissional entre os entrevistados. Em alguns relatos é revelada a característica provisória da ocupação e, como conseqüência, a não-identificação com o projeto social em questão. A inserção dos jovens nos projetos serviria como "ocupação" provisória e uma forma de suportar a condição de desempregado, visto que, a maioria dos entrevistados enfrenta dificuldade de inserção no mercado. Juntamente com essa concepção, o trabalho associativo funcionaria como uma espécie de espera para a entrada no mercado formal: enfim, uma vitrine das competências dos jovens. A utilização do local por alguns monitores do telecentro, com o objetivo de ter livre acesso à Internet e aos computadores, foi percebida nas falas. Assim, com o serviço disponível, o trabalhador realiza "bicos".

Alguns relatos apontam as amizades entre colegas e usuários como a principal motivação para o trabalho. Outros, no entanto, fundamentam seu vínculo de acordo com o ideal social; já que, engajados no projeto político da associação, vêem o trabalho como uma maneira de contribuir para sociedade. Dessa maneira, encaram a iniciativa com orgulho; pois seu fazer implica em diminuição da vulnerabilidade social. Nos relatos revelam que o sucesso do projeto possibilitaria um futuro melhor para a juventude da região.

Exemplos de engajamento político se evidenciam na opção por trabalhar voluntariamente em virtude de uma identificação ideológica, de um compromisso social que gratifica. Um participante relata que preferiu largar empregos mais "garantidos", pois acabou se tornando um refém do trabalho e do chefe. Ele diz: "o próprio patrão te via como um cifrão ou algum dinheiro, eles não te viam como pessoa, e acabavam te botando a trabalhar, tu trabalhava sábado, domingo, de madrugada, não queriam saber se tu tá cansado, ou se tu tem outra coisa para fazer". Portanto, seu envolvimento está ligado ao objetivo de desenvolver outras atividades mais plenas de sentido, incluindo aqui seu papel na associação e participação em movimentos sociais. Nesse exemplo vislumbramos uma exceção em relação aos outros entrevistados, visto que existe um projeto de vida situado no interior de uma postura coletivista e solidária. Já os outros entrevistados afirmam dar preferência por uma vaga em uma empresa tradicional com carteira assinada.

Uma das conclusões a que chegamos é de que o engajamento em relação ao projeto se relaciona ao suporte familiar para o sustento. A ausência ou não de suportes de proximidade (Castel, 1998) influencia na possibilidade de engajamento político, fazendo com que aqueles jovens que possuem alguma forma de suporte familiar e que não sejam responsáveis pelo sustento da família identifiquem-se mais com os princípios dos projetos. Portanto, percebe- 
Nardi, H.C., Yates, D.B., Fernandes, J.M., \& Carpenedo, M. (2006). Subjetividade e Solidariedade: A Diversidade das Formas de Implicação dos Jovens na Economia Solidária.

mos que, assim como os demais empreendimentos solidários, as associações voluntárias possuem semelhanças no que se refere às formas de identificação com o projeto social.

Entre os participantes entrevistados, notamos uma espécie de prolongação da relação de dependência financeira; visto que esses são jovens que não conseguem uma colocação no mercado formal. Essa não-emancipação ilustra não só a dificuldade de inserção profissional, mas também a utilização do voluntariado (ou esquema de bolsas) como maneira de se sentir útil e aplacar o sofrimento associado ao não ingresso no mercado de trabalho.

Quanto aos atributos de um trabalhador com boas chances no mercado de trabalho, são citadas virtudes como: a responsabilidade, competência, atualização, aparência física e a necessidade do diploma de curso superior e de especializações. Como nos outros grupos, a maioria dos entrevistados desenhou atributos que eles próprios não possuíam (os jovens concluíram o nível médio e alguns tinham curso técnico, mas não tiveram acesso à formação superior), conseqüentemente, a ilustração de um trabalhador com poucas chances no mercado de trabalho corres-pondia a sua situação.

Os entrevistados relataram dificuldade de planejar o futuro em longo prazo. Um dos fatores responsáveis seria o pessimismo decorrente das tentativas frustradas de inserção no mercado. Sendo assim, vislumbramos, nesse ponto, os percalços que envolvem esses jovens em relação a sua inserção profissional, já que se sentem impotentes para traçar metas no que se refere às suas carreiras.

\section{Discussão}

A proposta idealizada pelo movimento da economia solidária se constrói em oposição ao individualismo competitivo que caracteriza o comportamento econômico nas sociedades capitalistas. Entretanto, constatamos que os princípios da autogestão, considerados essenciais para a efetivação da ES não são plenamente alcançados nos empreendimentos analisados.

No caso do galpão de triagem, mesmo havendo a repartição igualitária da renda obtida com a produção, predomina a centralização do poder, ferindo o princípio da igualdade de direitos entre os sócios e reproduzindo relações autoritárias. Soma-se a isso o baixo retorno financeiro percebido pelos associados, o que ocasiona reduzida adesão ao projeto e alta rotatividade. A inserção no trabalho se dá pela necessidade de sobrevivência, sendo raro o engajamento por motivação política, como é desejado pelos idealizadores do movimento da ES

O mesmo ocorre na cooperativa metalúrgica, principalmente entre os trabalhadores da produção. A organização desse empreendimento é marcada pela hierarquização entre as funções dirigentes e de produção, com a reprodução da relação de quem pensa e de quem executa. A remuneração desigual entre os setores pode ser compreendida como uma valoração distinta das funções. Essa assimetria entre os cooperativados leva a uma contradição na forma de engajamento político dos trabalhadores que defendem a autogestão, mas não conseguem efetivá-la plenamente.

A partir dos relatos fica evidente a necessidade dos empreendimentos construírem uma maior estabilidade financeira e formas de proteção do trabalhador nos moldes dos direitos trabalhistas (férias, $13^{\circ}$ salário, cober tura previdenciária, etc.). Esses fatores proporcionariam uma maior possibilidade de implicação com o trabalho e seu objetivo social funcionando como suporte social (Castel, 1998). Este fator é de extrema relevância, pois as regiões urbanas onde se situam os projetos são marcadas pela pobreza, desemprego e baixa qualidade dos equipamentos públicos (escolas, serviços de saúde e segurança, por exemplo).

Percebemos uma diversidade nas formas de implicação profissional entre os entrevistados, característica também assinalada por Rosenfield (2003) e Gaiger (2004b). Entretanto, na maior parte dos relatos, fica evidente a perspectiva da provisoriedade do vínculo, configurando-se como uma alternativa ao desemprego e, ao mesmo tempo, como reconhecimento social, pois o sujeito passa a ser visto como um trabalhador e não como desempregado. Como exceção, encontramos os relatos de jovens que estão mais engajados nos projetos devido à identificação política com os princípios da ES.

No que se refere ao ideal profissional, nos três empreendimentos estudados percebemos, sob formas diferentes, uma tensão entre o desejo dos entrevistados e as formas encontradas para entrada no mercado de trabalho. Os jovens que precisaram trabalhar mais cedo por dificuldades financeiras têm, em sua maioria, um nível de escolaridade mais baixo e trabalham no galpão de triagem ou no setor da produção da cooperativa industrial. Entre aqueles que têm um suporte familiar mais estável (trabalhadores do telecentro e da direção da fábrica), a inserção se deu mais tarde e por iniciativa dos jovens, os quais buscavam obter experiência profissional e satisfação pessoal. Esta possibilidade maior de escolher se associa, invariavelmente, à existência de suportes familiares.

O que percebemos nos empreendimentos é que a aspiração da maioria dos trabalhadores entrevistados, especialmente aqueles que se encontram em uma situação sócio-econômica mais vulnerável, é conseguir emprego em uma empresa tradicional, apontada como fonte de estabilidade financeira. Obter uma renda estável é certamente um elemento determinante para uma implicação no trabalho pensada no longo prazo. Podemos ilustrar esta conclusão no relato dos jovens que optariam por manter-se na ES se as condições fossem melhores (proteção, estabilidade, renda). Entretanto, as condições, principalmente a remuneração, impõem a provisoriedade do engajamento. Esta frustração decorrente da precariedade do vínculo se expressa nos planos para o futuro, nos quais a insegurança impossibilita o planejamento da vida como forma de construir um futuro melhor. Aqui localizamos a principal contradição que marca a implicação nos projetos, ou seja, ao mesmo tempo em que os idealizadores do movimento afirmam a necessidade da implicação plena dos trabalhadores para que os princípios 
da autogestão se efetivem e para que o empreendimento tenha sucesso, os jovens necessitam de uma estabilidade maior para arriscar um engajamento mais importante, criando assim um ciclo vicioso de difícil resolução.

Cabe ressaltar que a pesquisa remete a um período especifico na história de vida dos projetos e dos jovens entrevistados e que nossas conclusões remetem a uma fotografia do momento pesquisado. Neste sentido, dois fatores que marcaram o final de nossa permanência no campo de pesquisa podem indicar uma nova forma de implicação dos jovens nos projetos. O primeiro foi o recebimento de bolsas-trabalho e a ampliação do investimento em formação para os trabalhadores do galpão de triagem, o segundo foi um empréstimo de grande vulto do Banco Nacional de Desenvolvimento Econômico e Social (BNDES) conquistado pela cooperativa industrial que permitirá o investimento tecnológico na produção. Estes incentivos aos projetos potencializam a garantia de uma geração de renda mais estável, possibilitando as condições materiais para que os jovens possam vislumbrar uma perspectiva de inserção em longo prazo.

\section{Referências}

Albuquerque, P. P. (2003). Autogestão. In A. D. Cattani (Ed.), $A$ outra economia (pp. 20-26). Por to Alegre, RS: Veraz.

Bauman, Z. (2000). Liquid modernity. Cambridge, UK: Polity Press.

Boltanski, L., \& Chiapello, E. (1999) Le nouvel esprit du capitalisme. Paris: Gallimard.

Bourdieu, P. (Ed.). (1993). La misère du monde. Paris: Seuil.

Cabanes, R. (2002) Travail, famille, mondialisation: Récits de la vie ouvrière à São Paulo, Brésil. Paris: IRD.

Carvalho, I. C. M. (2003). Biografia, identidade e narrativa: Elementos para uma análise hermenêutica [Versão eletrônica]. Horizontes Antropológicos, 9(19), 283-302. Retirado em http:/ /www.scielo.br/scielo.php?script= sci_arttext\&pid=So 10471832003000100012

Castel, R. (1998). As metamorfoses da questão social: Uma crônica do salário. Petrópolis, RJ: Vozes.

Colbari, A. L. (1995). Ética do trabalho: A vida familiar na construção da identidade profissional. São Paulo, SP: UFES.

Cruz, A. (2002). Uma contribuição crítica às políticas pú-blicas de apoio à economia solidária. Campinas, SP: Univer sidade Estadual de Campinas. Retirado do Grupo de Pesquisas em Economia Solidária: http://www.ecosol.org.br/txt/politpub.doc

Durand, J. P. (2003). A refundação do trabalho no fluxo tensionado. Tempo Social, 17 (1), 140-158.

Erhemberg, A. (2000). La fatigue d'être soi: Dépression et société. Paris: Odile Jacob.

Ferraz, D. L. S. (2004). Tricotando as redes de solidariedade - $A$ cultura organizacional de uma loja autogestionada de economia solidária de Porto Alegre. Trabalho de Conclusão de Curso nãopublicado, Faculdade de Administração, Universidade Federal do Rio Grande do Sul, Porto Alegre, RS.

Foucault, M. (1994). A propos de la généalogie de l'éthique: Un aperçu du travail en cours. In M. Foucault, Dits et ecrits (Vol. 4, pp. 383411). Paris: Gallimard.

Gaiger, L. I. (2004a). Apresentação. In L. I. Gaiger (Ed.), Sentidos e experiências da economia solidária no Brasil (pp. 7-15). Por- to Alegre, RS: Editora da Universidade Federal do Rio Grande do Sul.

Gaiger, L. I. (2004b). As Emancipações no presente e no futuro. In L. I. Gaiger (Ed.), Sentidos e experiências da economia solidária no Brasil (pp. 371-402). Porto Alegre, RS: Editora da Universidade Federal do Rio Grande do Sul.

Holzmann, L (2001). Operários sem patrão: Gestão cooperativa e dilemas da democracia. São Carlos, SP: Editora da Universidade Federal de São Carlos

Icaza, A. M. S., \& Tiriba, L. (2003). Economia popular. In A. D. Cattani (Ed.), A outra economia (pp. 101-109). Porto Alegre, RS: Veraz.

Laplanche, J., \& Pontalis, J.-B.(1998). Vocabulaire de la psychanalyse (2ème Ed.). Paris: PUF.

Laville, J. L. (1999). Une troisième voie pour le travail. Paris: Desclée de Brouwer.

Nardi, H. C. (2003). A propriedade social como suporte da existência: A crise do individualismo moderno e os modos de subjetivação contemporâneos. Psicologia e Sociedade, 15(1), 3756, 2003.

Nardi, H. C., Tittoni, J., \& Bernardes, J. (2002). Subjetividade e trabalho. In A. D. Cattani (Ed.), Dicionário crítico sobre trabalho e tecnologia (pp. 302-308). Petrópolis, RJ: Vozes.

Petras, J. (1999). Neoliberalismo: América Latina, Estados Unidos e Europa. Blumenau, SC: Editora da Universidade Regional de Blumenau.

Pires, M. L. L. S. (1999). Cooperativismo: Entre os ideais utópicos e as exigências da competitividade do mercado. Um estudo de caso de uma cooperativa frutícola no Vale de São Francisco. Perspectiva Econômica, 34(108).

Rosenfield, C. L. (2003). A autogestão e a nova questão social: Repensando a relação indivíduo-sociedade. Civitas, 3(2), 395415 .

Sennett, R. (1998). The corrosion of character: Personal consequences of work in the new capitalism. New York: W. W. Norton \& Company.

Singer, P. (2000). A economia solidária no Brasil: A autogestão como resposta ao desemprego. São Paulo, SP: Contexto.

Singer, P. (2003). Economia solidária. In A. D. Cattani (Ed.), $A$ outra economia. (pp. 116-125). Porto Alegre, RS: Veraz.
Recebido: 16/02/2005 $1^{a}$ revisão: $12 / 04 / 2005$ $2^{a}$ revisão: $13 / 10 / 2005$ Aceite final: 08/12/2005 